\title{
West Nile virus - Where did it come from and where might it go?
}

\author{
B Lynn Johnston MD FRCPC ${ }^{1}$, John M Conly MD FRCPC ${ }^{2}$
}

$\mathrm{I}$ n October 1999, the Centers for Disease Control and Prevention (CDC) reported on an outbreak of human arboviral encephalitis in New York City, beginning in late August (1). The encephalitis was initially thought to be due to St Louis encephalitis (SLE) virus because of positive serological results from the cerebrospinal fluid (CSF) and serum of affected patients. At the same time, there was an increase in avian mortality including wild crows and exotic birds at the Bronx Zoo (2). Because avian mortality is not common with SLE, other pathogenic arboviruses were investigated as the cause of this unusual phenomenon. Subsequent DNA sequencing of human and avian viral isolates indicated that they were closely related to West Nile (WN) virus, not previously isolated in the Western Hemisphere (1). Serological testing of CSF and serum, including those specimens positive for SLE virus, from a number of patients was positive for antibody to $\mathrm{WN}$ virus (3). A new infectious disease had emerged in the Americas.

$\mathrm{WN}$ virus is an arthropod-borne virus belonging to the Japanese encephalitis complex of the Flavivirus genus (4). Flaviviruses are lipid-enveloped, single stranded RNA viruses, with a genome of approximately 11,000 nucleotides. Flaviviruses belong to the family Flaviviridae with Pestivirus (of veterinary importance) being the other genus in this family. There are over 68 viruses in this genus, of which 30 are known to cause human disease (5). Within the genus, the flaviviruses are classified into distinct species or serotypes by antigenic distinctions. There are at least eight antigenic complexes, six of which contain human pathogens. Japanese encephalitis, SLE, Murray Valley encephalitis, Kunjin, Kokobera, Koutango, Usutu and WN viruses all belong to the Japanese encephalitis complex (4). Viruses within the Japanese encephalitis complex share up to $77 \%$ of their amino acid sequences, resulting in cross-reactive serological tests and providing an explanation for the original identification of the outbreak as due to SLE virus. Although the Flaviviruses are closely related antigenically and cross-react in serological tests with polyclonal antisera, most have a distinctive geographical distribution (6).

$\mathrm{WN}$ virus was first isolated in the $\mathrm{WN}$ province of Uganda in 1937 (7). The first recorded epidemics were reported in Israel in the 1950s $(8,9)$ and in Europe in 1962 (1). Sporadic cases and outbreaks have been reported from Africa $(10,11)$, India (12) and Romania (13). The virus is the most widely distributed of the arboviruses, causing infections in Africa, the Middle East and South Asia, where it is endemic, and in Europe more sporadically (13-15). However, it had never been identified in the Americas before 1999. A closely related serotype, Kunjin, has been found in Australia and Southeast Asia (15). Subtypes of WN virus are distinguished by antigenic variations in the envelope (E) protein and the presence of an $N$-glycosylation site at amino acids 154 to 156 (16). Two lineages have been proposed: lineage I includes Kunjin and WN virus from Europe, the Middle East, and North, Central and West Africa; and lineage II includes WN virus from West, Central and East Africa, and Madagascar. The complete nucleotide sequence of one of the viral isolates (from the dead Chilean flamingo at the Bronx zoo) was determined (6). Analysis showed it to be a lineage I WN virus (16), and most closely related to WN virus isolated recently from North Africa, Romania, Kenya, Italy and the Middle East (6). Lanciotti et al (6) demonstrated a high degree of sequence similarity among the various strains circulating throughout New York City and surrounding counties and states.

The ecology of WN virus has recently been described by Hubálek and Halouzka (15). Similar to other Flaviviruses, WN virus has an arthropod vector, which serves as a true biological vector. Mosquitoes, mainly bird-feeding species, are the principal vectors. WN virus has been isolated from 43 mosquito species, predominantly Culex but also Aedes and Anopheles species. Experimental and field evidence demonstrates vertical transmission from parent to offspring mosquitoes (17-19). While the exact role of vertical transmission is

${ }^{1}$ Queen Elizabeth II Health Sciences Centre and Dalhousie University, Halifax, Nova Scotia; ${ }^{2}$ University Health Network, University of Toronto, Toronto, Ontario

Correspondence and reprints: Dr Lynn Johnston, Room 5014 ACC, Queen Elizabeth II Health Sciences Centre, 1278 Tower Road, Halifax, Nova Scotia B3H 2Y9. Telephone 902-473-8477, fax 902-473-7394, e-mail ljohnsto@is.dal.ca and Dr John Conly, Department of Medicine, Division of Infectious Diseases, Suite 13-118 Norman Urquhart Wing, Toronto General Hospital, University Health Network, 200 Elizabeth Street, Toronto, Ontario M5G 2C4. Telephone 416-340-4858, fax 416-340-5047, e-mail john.conly@uhn.on.ca 
not known, it certainly offers the potential for persistence of the virus under unfavourable circumstances in overwintering mosquitoes. This would also make human infection possible in the absence of an active enzootic mosquito-to-bird transmission cycle $(17,19)$. Wild birds are the principal hosts. High, long term viremia has been observed in infected birds, with virus persistence in the organs of inoculated ducks and pigeons demonstrated for 20 to 100 days. Birds are usually asymptomatic. However, natural disease has been documented with encephalitis and death produced by inoculation of certain avian species. Of interest is that the WN-Israel 1998 virus, closely related genetically to the New York City strain, was associated with increased pathogenicity in birds (6). Mammals become incidentally infected and are less important in maintaining transmission. Horses develop fever and encephalomyelitis with a moderate to high fatality rate.

In Europe, two cycles involving WN virus have been described $(5,15)$. The first is a rural cycle involving wetland birds and mosquitoes, and the second an urban cycle with domestic birds and mosquitoes, with the mosquitoes feeding on both birds and humans. A similar dual cycle is seen with SLE virus in the United States with interaction of these two cycles, rural and urban (15). Genetic analysis of a WN virus mosquito isolate from Romania showed the identical sequence to isolates from mosquitoes from Senegal and Kenya, and part of a lineage composed of strains from North, West, Central and East Africa, all of the European isolates and an Israeli isolate (20). It has been hypothesized that virus was introduced to Europe by birds migrating from sub-Saharan Africa to northern Africa and then to southern Europe. This theory is supported by transfer of another virus, Sindbis virus, from South Africa to northern Europe by migratory birds, as well as by isolation of WN virus from migratory birds and their ticks in Europe (13). Northward migration of birds occurs along the Danube Delta, a main avian refuge.

Environmental factors that enhance vector proliferation and its contact with host animals and humans allow the emergence of WN virus. Risk factors for acquiring $\mathrm{WN}$ virus in the Romanian outbreak were mosquitoes in the home, more mosquito bites per day and, for people living in apartments, having a flooded basement (21). An abundance of indoor mosquitoes was noted in Bucharest residences during the outbreak, probably related to a scarcity of home air conditioners and screens. Apartment building basements, flooded with sewage leaking from poorly maintained plumbing, provided a good breeding ground for mosquito larvae (21). Additionally, chickens and other domestic fowl (with a seroprevalence of $41 \%$ ) were commonly kept at private residences in Bucharest (13).

In the New York City outbreak, the initial cases lived within a $3.2 \mathrm{~km}$ radius of one another and in close proximity to the two major international airports (3). Cases were subsequently found in two neighbouring counties (1). Only one of the patients had travelled to Africa, in June 1999. Just before and concurrent with the human outbreak was an increased number of deaths in birds, especially crows (1). This high mortality is suggestive of the recent introduction of virus to the area (16). Subsequent studies found infected birds and mos- quitoes in several counties north of New York City, Long Island, New Jersey (22) and Connecticut (23). A November 1999 workshop on the WN virus outbreak reported that virus had been isolated from a dead crow in Baltimore (22). More recently, an infected hawk was found in a suburb north of New York City in February 2000 (24). This suggests that the maintenance hosts and arthropod vectors are fairly widely distributed (16). These findings have raised concerns that WN virus may become established in avian fauna of the United States (23), as well as questions of whether migrating birds will spread it to the southwestern United States, Caribbean and even South America (22).

One important question has been whether WN virus might persist through the winter, with reintroduction of the transmission cycle in the spring of 2000. It had been speculated that the New York City subway system could be a winter haven for infected mosquitoes (22). To answer this question, overwintering Culex mosquitoes have been collected from several areas in New York City. To date, three of the 67 mosquito pools collected have had low (detected only by polymerase chain reaction, not by culture) but detectable levels of WN virus RNA (25). It is, as yet, unknown whether WN virus persisted over the winter in the New York area.

How WN virus arrived in New York City is unknown. Potential routes of introduction include importation of infected birds, mosquitoes or viremic human beings. The outbreak occurred in an area including two international airports (16). Incidental hosts, such as humans, are not believed to be involved in transmission (4). Although exotic birds at the Bronx Zoo could be considered a potential source, no birds had been imported by the zoo for more than six months before the outbreak, and birds outside the zoo were dying before zoo birds (26). Thus, zoo birds were an unlikely source. Birds destined for pet shops would have died in quarantine, raising the possibility of illicit importations as another source (26).

In regions where $\mathrm{WN}$ virus is endemic, many infections are not apparent or cause only mild disease. Acquired immunity likely represents a barrier to epidemics. Human outbreaks, sometimes with severe disease, are probably the result of the introduction of the virus to areas or into populations where background immunity is low $(4,10)$. Historically, the illness caused by $\mathrm{WN}$ virus has been described as an acute, febrile, influenza- or dengue-like illness lasting three to six days, with moderate to high fever, headache, backache, myalgia and arthralgia $(4,8,15)$. The incubation period is reported to be five to 15 days (3). Not uncommon are rash, generally described as roseolar or maculopapular in nature, and lymphadenopathy. Complications are reported in less than $15 \%$ and include central nervous system involvement (aseptic meningitis or encephalitis, anterior myelitis), hepatitis, pancreatitis and myocarditis. In the early literature, recovery was reported as complete and permanent sequelae not noted $(8,9)$. However, deaths due to $\mathrm{WN}$ virus have been reported in the Romanian $(13,21)$, Algerian (11) and New York City (3) outbreaks and, as early as 1984, in three children in India (12). Variations in the expression of disease may also be related to strain-specific differences in virulence genes (4). 
Two recent epidemics of WN virus have allowed a more detailed description of the clinical features of the epidemic form of disease $(3,13,21)$. Between July and October 1996, an epidemic of WN virus, the first in an urban setting, occurred in Bucharest and the lower Danube Valley of southeastern Europe (13). In this epidemic, characterized clinically by neurological involvement, 835 patients met the case definition. of 393 patients with laboratory-confirmed $\mathrm{WN}$ virus infection and neurological involvement, 40\% had meningitis, 44\% meningoencephalitis and $16 \%$ encephalitis. In a case control study, the risk of developing meningoencephalitis was not associated with an underlying medical condition, but was correlated with outdoor activity (21). The onset of illness was abrupt, with fever (91\%), headache (77\%), neck stiffness (57\%), vomiting (53\%), chills (45\%), confusion (34\%), and ataxia and extrapyramidal signs (17\%). Progression to coma occurred in $13 \%$ of patients, and there were 17 deaths, for a case fatality rate of $4.3 \%$. All deaths were in patients over the age of 50 years. The population-based incidence of cases was four/100,000. A serosurvey of 959 asymptomatic outpatients showed that $4.1 \%$ had immunoglobulin (Ig) G to WN virus. Based on serology, the rate of asymptomatic to clinical infection was estimated at 140:1 to $320: 1$.

In the New York City outbreak, there had been 62 laboratory-confirmed cases with seven deaths, as of March 2000 (27). One of the deaths was a 75-year-old Canadian who had visited New York City in September 1999 and subsequently died after returning home (28). More than $60 \%$ of patients were over 65 years of age, and only two were children (28). To determine how many people had been infected with WN virus in northern Queens, the New York Department of Health conducted an anonymous serosurvey in the fall of 1999. It found that 19 of 677 blood samples (or approximately $2.6 \%$ of the population, $95 \%$ CI $1.2 \%$ to $4.1 \%$ ) tested positive for antibodies to WN virus (27). Only $30 \%$ of those who tested positive reported symptoms suggesting a recent infection.

Asnis et al (3) described the disease in eight patients with central nervous system involvement, six with encephalitis and two with meningitis. The encephalitis patients were older and had a more severe presentation than the two with meningitis. of the six encephalitis patients, all were confused and five had temperatures above $39^{\circ} \mathrm{C}$, gastrointestinal symptoms and muscle weakness; four had abnormalities on electromyelogram/nerve conduction studies. All six had abnormal CSF, six with elevated protein and five with CSF pleocytosis (lymphocyte predominance in four). Four patients required ventilator support and three died. The two with meningitis were mentally intact, had good strength, CSF pleocytosis and elevated protein, and made a full recovery. All eight had serological diagnosis by demonstration of IgM for WN virus by ELISA and confirmed by plaque-reduction neutralizing antibody assay to exclude other cross-reacting flaviviruses.

A variety of diagnostic tests is available for $\mathrm{WN}$ virus infection. Virus may be isolated from blood for up to 10 days in the immunocompetent and for up to 22 to 28 days in the immunocompromised (15). In patients with neurological disease, virus can also be isolated from CSF and brain tissue. A variety of cell lines support growth of the virus (4). The diagnosis can also be confirmed by demonstration of viral antigen or genomic sequences in tissue, blood and CSF. Immunohistochemical staining will detect flaviviral antigen of the Japanese encephalitis complex. One of the preferred diagnostic methods is IgM detection in serum or CSF by an antibody-capture ELISA. Because of cross-reactions with other flaviviruses, these must be excluded by the plaque-reduction neutralization antibody test for IgG antibody. Serial rising titres can also be shown by complement fixation, neutralizing antibody and hemagglutination inhibition. In Canada, serological testing by hemagglutination inhibition and neutralization, polymerase chain reaction and virus isolation is available from the Laboratory Centre for Disease Control in Winnipeg, Manitoba. Serological testing is also available through the Ontario Public Health Laboratory (personal communication, Dr Harvey Artsob, Canadian Centre for Human and Animal Health, Winnipeg, Manitoba).

Sampson et al (29) reported the neuropathology results of four fatalities from the New York City outbreak. All four had scattered microglial nodules composed of lymphocytes and histiocytes in the white and grey matter, with a predilection for the brainstem. The thalamus, cerebellum and cortex were involved less frequently and less intensely. A mononuclear, perivascular inflammatory infiltrate was present in a similar distribution. Leptomeningitis was present in two patients, and mononculear inflammation around cranial nerve roots in two patients. The spinal cord was not examined.

A number of lessons were learned from the WN virus outbreak. The possibility of an outbreak was raised by an infectious disease physician who diagnosed encephalitis in two patients from the same geographical area (1). This is a reminder that a very small cluster of unusual infections is enough to warrant a call to the public health authorities (26). It is also testimony to an astute clinician. Before and concurrent with the human cases, local health officials had noted an increased number of deaths in birds, especially crows (1). This latter finding serves as another reminder that unusual diseases in animals can be sentinels of human outbreaks (26). Communication links between human and veterinary medical professionals need to be better. The potential for international travel to result in an emerging infectious disease was clearly demonstrated. Finally, the rapid institution of effective control measures speaks for the importance of public health and emergency response medicine, even in this modern age (26). Although the initial diagnosis was incorrect, the authorities were suspicious of a flavivirus, and quickly proceeded to institute aerial and ground applications of mosquito adulticides and larvacides, with no further cases diagnosed (1). In addition to the spraying program, measures were taken for surveillance for human disease, mosquito surveillance, establishment of telephone hotlines, and distribution of informational leaflets and $N, N$-diethyl-m-toluamide (DEET) (through local firehouses). It was suggested that successful implementation of the control program was due to openness by the city officials, including the mayor and public health and emergency response officials, rapid publicity at the local level and sensible reporting of the outbreak by the media (26). 
In January 2000, guidelines, developed by the CDC and United States Department of Agriculture to monitor WN virus activity and to prevent future outbreaks, were published in the Morbidity and Mortality Weekly Report (30). They include recommendations for surveillance activities, laboratory diagnosis, prevention and control, public health infrastructure, interjurisdictional data sharing and research priorities. There will be active bird surveillance of both wild and sentinal bird populations along the migration path from Massachusetts to Texas along the Atlantic and Gulf coasts, enhanced mosquito surveillance, and enhanced passive veterinary and human surveillance for neurological disease. Serological testing for WN virus is to be available at all state, and public health and veterinary laboratories.

Might we expect an outbreak of WN virus in Canada? Canada has both the appropriate mosquito vectors and vertebrate reservoir hosts. It is unknown, however, whether $\mathrm{WN}$ virus moved south during the fall bird migration and/or whether it will move in the spring to northern ecologies such as the Ottawa River Valley, southern Ontario and Quebec, or eastern or western Canada where appropriate mosquito vectors are well established (28). The occurrence of WN virus infection in Canada must be considered a real possibility, warranting a high index of suspicion on the part of Canadian physicians. In February 2000, Health Canada convened a working group meeting to assess the risk of introduction of $\mathrm{WN}$ virus into Canada. A subcommittee was established to develop and refine further recommendations on animal and mosquito surveillance, human surveillance, laboratory diagnosis, biosafety and communications, with another committee formed to address implementation of the WN virus subcommittee's recommendations (28). The federal Departments of Health and Environment, and the Canadian Food Inspection Agency, provincial Ministries of Health, committees and associations with interests in wildlife, health and agriculture, as well as the $\mathrm{CDC}$ and other United States agencies, are working to have a coordinated approach to address the potential risk of $\mathrm{WN}$ virus. Many provinces have implemented surveillance for WN virus.

\section{REFERENCES}

1. Outbreak of West Nile-like viral encephalitis - New York, 1999. MMWR Morb Mortal Wkly Rep 1999;48:845-9.

2. Briese T, Jia XY, Huang C, Grady LJ, Lipkin WI. Identification of a Kunjin/West-Nile-like flavivirus in brains of people with New York encephalitis. Lancet 1999;354:1261-2.

3. Asnis DS, Conetta R, Teixeira AA, Waldman G, Sampson BA. The West Nile virus outbreak of 1999 in New York: the Flushing Hospital experience. Clin Infect Dis 2000;30:413-8.

4. Monath TP, Tsai TF. Flaviviruses. In: Richman DD, Whitley RJ, Hayden FG, eds. Clinical Virology. Philadelphia: Churchill Livingstone, 1997:1133-85.

5. Tsai TF. Flaviviruses (Yellow fever, dengue hemorrhagic fever, Japanese encephalitis, St Louis encephalitis, tick-borne encephalitis). In: Mandell GL, Bennett JE, Dolin R, eds. Principles and Practice of Infectious Diseases, 5th edn. Philadelphia: Churchill Livingstone, 1999:1714-36.

6. Lanciotti RS, Roehrig JT, Deubal V, et al. Origin of the West Nile virus responsible for an outbreak of encephalitis in the northeastern United States. Science 1999;286:2333-7.
7. Smithburn KC, Hughes TP, Burke AW, et al. A neurotropic virus isolated from the blood of a native of Uganda. Am J Trop Med Hyg 1940;20:471-92.

8. Marberg K, Goldblum N, Sterk VV, Jasinska-Klingberg W, Klingberg MA. The natural history of West Nile fever. Clinical observations during an epidemic in Israel. Am J Hyg 1956;64:259-69.

9. Goldblum N, Sterk VV, Paderski B. West Nile fever. The clinical features of the disease and the isolation of West Nile virus from the blood of nine human cases. Am J Hyg 1954;59:89-103.

10. Nur YA, Groen J, Heuvelmans H, Tuynman W, Copra C, Osterhaus AD. An outbreak of West Nile fever among migrants in Kisangani, Democratic Republic of Congo. Am J Trop Med Hyg 1999;61:885-8.

11. Le Guenno B, Bougermouh A, Azzam T, Bouakaz R. West Nile: a deadly virus? Lancet 1996;348:1315.

12. George S, Gourie-Devi M, Rao JA, Prasad SR, Pavri KM. Isolation of West Nile virus from the brains of children who had died of encephalitis. Bull WHO 1984;62:879-82.

13. Tsai TF, Popovici F, Cernescu C, Campbell GL, Nedelcu NI for the Investigation Team. West Nile encephalitis epidemic in southeastern Romania. Lancet 1998;352:767-71.

14. Corwin A, Habib M, Watts D, et al. Community-based prevalence profile of arboviral, rickettsial, and Hantaan-like viral antibody in the Nile River Delta of Egypt. Am J Trop Med Hyg 1993;48:776-83.

15. Hubálek Z, Halouzka J. West Nile fever - A reemerging mosquitoborne viral disease in Europe. Emerg Infect Dis 1999;5:643-50.

16. Jia XY, Briese T, Jordan I, et al. Genetic analysis of West Nile New York 1999 encephalitis virus. Lancet 1999;354:1971-2.

17. Miller BR, Nasci RS, Godsey MS, et al. First field evidence for natural vertical transmission of West Nile virus in Culex univittatus complex mosquitoes from Rift Valley province, Kenya. Am J Trop Med Hyg 2000;62:240-6.

18. Rosen L. Further observations on the mechanism of vertical transmission of flaviviruses by Aedes mosquitoes. Am J Trop Med Hyg 1988;39:123-6.

19. Baqar S, Hayes CG, Murphy JR, Watts DM. Vertical transmission of West Nile virus by Culex and Aedes species mosquitoes. Am J Trop Med Hyg 1993;48:757-62.

20. Savage HM, Ceianu C, Nicolescu G, et al. Entomologic and avian investigations of an epidemic of West Nile fever in Romania in 1996, with serologic and molecular characterization of a virus isolate from mosquitoes. Am J Trop Med Hyg 1999;61:600-11.

21. Han LL, Popovici F, Alexander JP Jr. Risk factors for West Nile virus infection and meningoencephalitis, Romania, 1996. J Infect Dis 1999;179:230-3.

22. Enserink M. New York's lethal virus came from Middle East DNA suggests. Science 1999;286:1450-1.

23. Anderson JF, Andreadis TG, Vossbrinck CR. Isolation of West Nile virus from mosquitoes, crows, and a cooper's hawk in Conneticut. Science 1999;286:2331-3.

24. Enserink M. New York's deadly virus may stage a comeback. Science 2000;287:2129-30.

25. Update: Surveillance for West Nile virus in overwintering mosquitoes - New York, 2000. MMWR Morb Mortal Wkly Rep 2000;49:178-9

26. Exotic diseases close to home. Lancet 1999;354:1221. (Edit)

27. New York City Department of Health. West Nile Virus questions and answers on serosurvey. <http://www.ci.nyc.ny.us/html/doh/html/wnv/wnvga.html> (Version current at June 28, 2000).

28. Health Canada. West Nile Virus Surveillance Information. <http://www.hc-sc.gc.ca/hpb/lcdc/bid/wnv/index.html> (Version current at June 28, 2000).

29. Sampson BA, Ambrosi C, Charlot A, Reiber K, Veress JF, Armbrustmacher V. The pathology of human West Nile virus infection. Hum Pathol 2000;31:527-31.

30. Guidelines for surveillance, prevention and control of West Nile virus infection - United States. MMWR Morb Mortal wkly Rep 2000;49:25-8. 


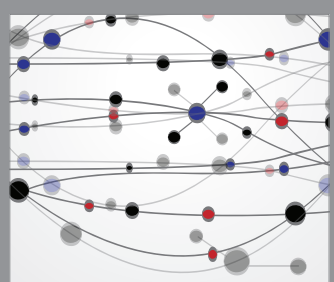

The Scientific World Journal
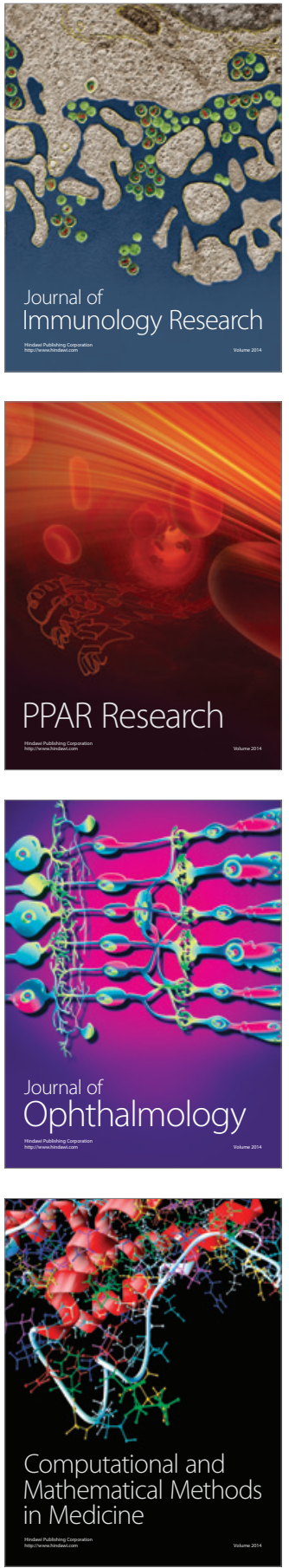

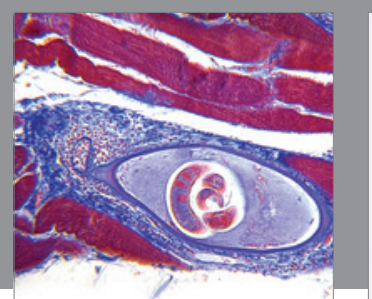

Gastroenterology Research and Practice

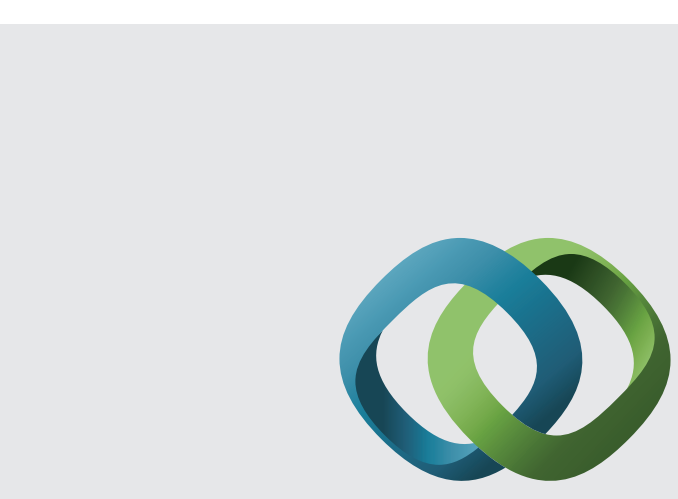

\section{Hindawi}

Submit your manuscripts at

http://www.hindawi.com
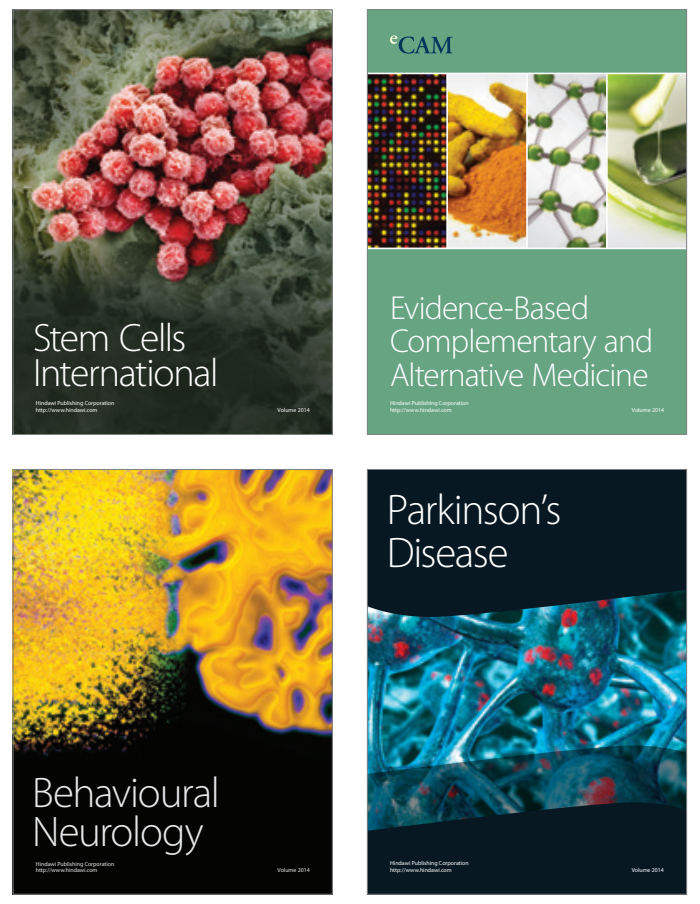
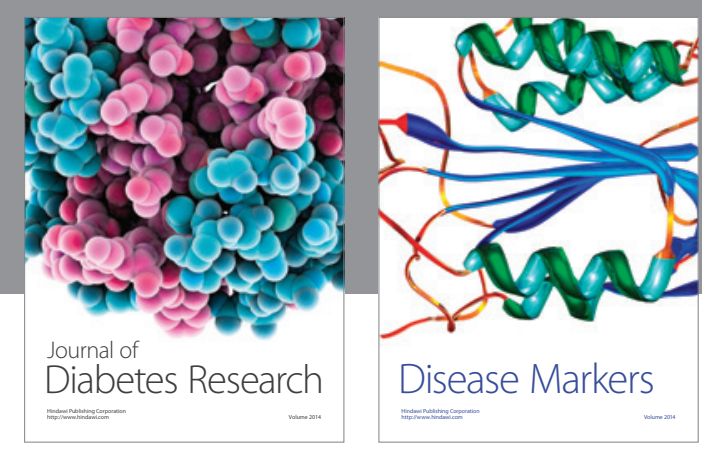

Disease Markers
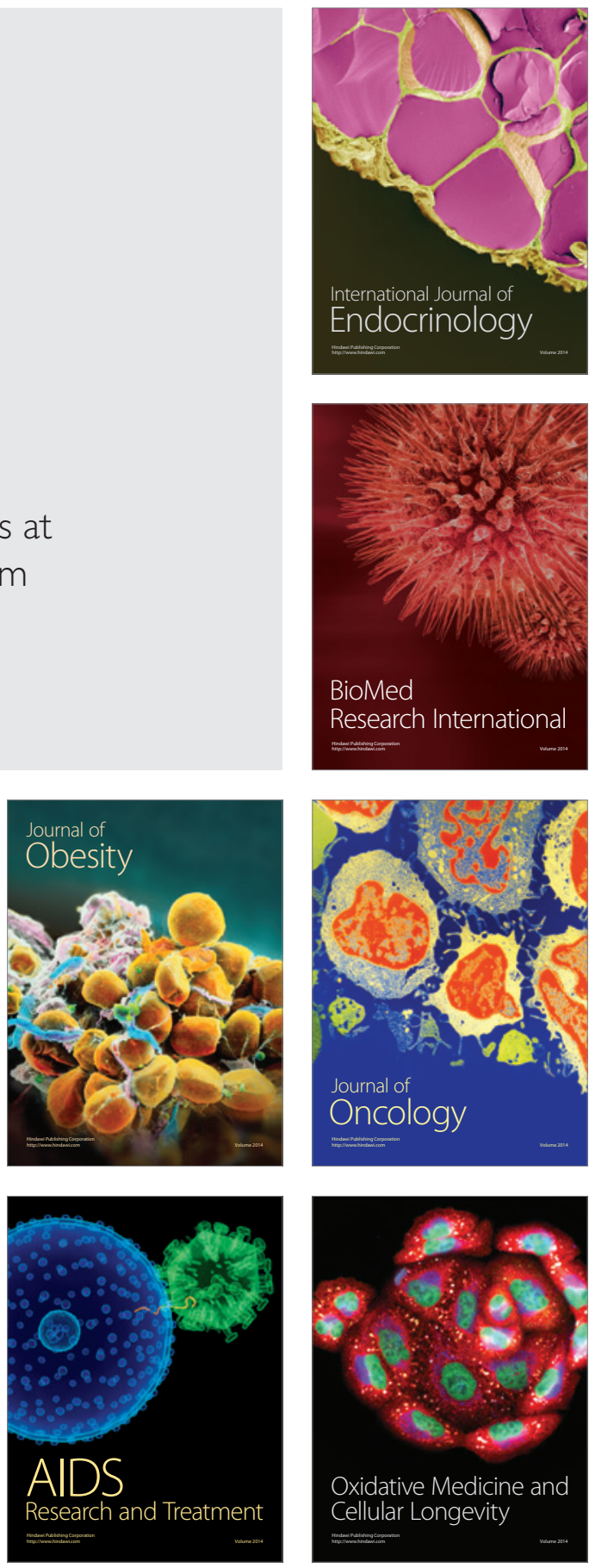